\title{
PENGARUH METODE EKSPOSITORI PADA PEMBELAJARAN MATEMATIKA DASAR MAHASISWA MANAJEMEN PENDIDIKAN ISLAM
}

\author{
Tika Karlina Rachmawati \\ Prodi Pendidikan Matematika, FTK, UIN Sunan Gunung Djati Bandung \\ email: tikakarlinarachmawati@uinsgd.ac.id
}

\begin{abstract}
Basic Mathematics is one of the subjects that must be taken by students of Islamic Education Management Studies Program of first semester in UIN Sunan Gunung Djati Bandung. Most graduates of students who enter the Islamic Education Management Studies Program is a graduate of SMK or SMA majoring in social studies. Therefore, the researcher applies an escapitory method to teach Basic Mathematics courses in MPI. The purpose of this study is to determine the influence of expository methods in the basic mathematics courses in Islamic education management program. The population in this study is the students of Islamic education management study semester one with the sampling taken with purposive sampling technique so that the sample obtained one class that is class A which amounted to 39 students. The research method used is pseudo experiment. Data collection techniques using pretest and postest. The assumption test includes the data normality test using the Liilefors test. Data analysis using Wilcoxon test. Based on the Wilcoxon test output it is known that Asymp Sig (2tailed) is worth 0.000. Because the value $0.000<0.05$ then it can be interpreted that there is a difference between the basic mathematics skills test before the students were given the expository method. The result of the research shows that there is influence of expository method in the elementary mathematics course in Islamic education management student.
\end{abstract}

Keywords: Expository, Pretest, Posttest, Basic Mathematic

\begin{abstract}
Abstrak: Matematika Dasar merupakan salah satu mata kuliah yang wajib ditempuh mahasiswa Program Studi Manajemen Pendidikan Islam semester satu di UIN Sunan Gunung Djati Bandung. Kebanyakan lulusan mahasiswa yang masuk ke Program Studi Manajemen Pendidikan Islam merupakan lulusan SMK atau SMA jurusan IPS. Oleh karena itu, peneliti menerapkan metode eskpositori untuk mengajarkan mata kuliah Matematika Dasar di MPI. Tujuan penelitian ini adalah untuk mengetahui pengaruh metode ekspositori pada mata kuliah Matematika Dasar di Prodi Manajemen Pendidikan Islam. Populasi pada penelitian ini adalah mahasiswa prodi manajemen pendidikan islam semester satu dengan pengambilan sampel diambil dengan teknik purposive sampling sehingga didapatkan sampel satu kelas yaitu kelas A yang berjumlah 39 mahasiswa.Metode penelitian yang digunakan yaitu eksperiment semu. Teknik pengumpulan data dengan menggunakan pretest dan posttest. Uji asumsi meliputi uji normalitas data dengan menggunakan uji Liilefors. Analisis data menggunakan uji Wilcoxon. Berdasarkan output uji Wilcoxon diketahui bahwa Asymp Sig (2-tailed) bernilai 0,000. Karena nilai $0,000<0,05$ maka dapat diartikan bahwa ada perbedaan antara tes kemampuan matematika dasar mahasiswa sebelum dengan sesudah diberi metode ekspositori. Hasil penelitian menunjukan ada pengaruh metode ekspositori pada mata kuliah matematika dasar pada mahasiswa manajemen pendidikan islam.
\end{abstract}

Kata Kunci: Ekspositori, Pretest, Posttest, Matematika Dasar 


\section{PENDAHULUAN}

Matematika Dasar merupakan salah satu mata kuliah wajib yang ditempuh oleh mahasiswa semester satu pada Prodi Manajemen Pendidikan Islam (MPI) di UIN Sunan Gunung Djati Bandung. Mata kuliah ini berbobot 2 sks. Rata-rata mahasiswa pada prodi Manajemen Pendidikan Islam tidak menyukai pelajaran matematika karena bakground mereka pada waktu di SMA adalah lulusan SMK atau SMA jurusan Sosial. Untuk itu, peneliti mencari metode yang cocok untuk diterapkan pada pembelajaran matematika dasar di Prodi MPI. Salah satu metode yang cocok adalah metode ekspositori.

Menurut Hudoyo (1998), metode ekspositori meliputi gabungan dari ceramah, driil, tanya jawab, penemuan, dan peragaan. Sedangkan Suyitno (2004), mengemukakan bahwa metode ekspositori ialah cara penyampaian pelajaran dari seorang guru kepada siswa di kelas dengan cara berbicara pada awal pembelajaran, menerangkan materi, memberikan contoh soal disertai tanya jawab dan siswa hanya mendengarkan dan membuat catatan. Metode ekspositori merupakan salah satu metode pembelajaran yang memungkinkan siswa belajar secara maksimal untuk memecahkan masalah. Oleh karena itu metode pembelajaran ekspositori menekankan pada proses penyampaian secara verbal dari guru kepada siswa dengan tujuan agar siswa menguasai materi pelajaran secara optimal (Sanjaya, 2006). Sedangkan penelitian yang dilakukan Ardhiansyah (2017) menghasilkan bahwa metode ekspositori merupakan metode yang dapat meningkatkan hasil belajar matematika.

Tahapan-tahapan pembelajaran dengan menggunakan metode ekspositori sebagai berikut.
1. Persiapan

Pada tahap persiapan ini meliputi dosen memberikan sugesti positif atau motivasi kepada mahasiswa serta mengemukakan tujuan dan materi yang akan disampaikan.

2. Penyajian

Pada tahap penyajian ini meliputi menjelaskan isi materi, memberikan contoh-contoh soal beserta penyelesaiannya, melakukan tanya jawab.

3. Penutup

Pada tahap ini meliputi menyimpulkan inti sari dari materi yang telah diperlajari, kemudian memberikan tes atau soal latihan yang sesuai dengan materi yang telah dibahas.

Kelebihan dari dilaksanakannya metode ekspositori adalah guru dapat mengontrol urutan dan keluasan materi pembelajaran, metode ini efektif apabila materi yang harus dikuasai siswa cukup luas, sementara waktu yang dimiliki terbatas. Disamping ada kelebihan, metode ekspositori juga mempunyai kelemahan, yaitu metode ini dapat dilakukan kepada siswa yang memiliki kemampuan mendengar dan menyimak dengan baik, sulit mengembangkan kemampuan siswa karena metode ini lebih banyak ceramahnya, keberhasilan metode ini sangat tergantung kepada kemampuan guru, metode ini tidak dapat melayani perbedaan setiap siswa baik perbedaan kemampuan, pengetahuan, maupun minat. Oleh karena itu, peneliti ingin mengetahui apakah penerapan metode ekspositori akan berpengaruh pada pembelajaran mata kuliah Matematika Dasar.

Tujuan penelitian ini adalah untuk mengetahui pengaruh metode ekspositori pada mata kuliah Matematika Dasar di Prodi Manajemen Pendidikan Islam. 


\section{METODE PENELITIAN}

Penelitian ini merupakan penelitian quasi eksperiment. Populasi penelitian ini adalah mahasiswa semester satu Prodi Manajemen Pendidikan Islam (MPI) dengan jumlah 83 mahasiswa yang terbagi menjadi 2 kelas yaitu kelas A sebanyak 39 mahasiswa dan kelas B sebanyak 44 mahasiswa. Sampel diambil dengan teknik purposive sampling yaitu kelas A dengan jumlah 39 mahasiswa. Instrumen penelitian yang digunakan adalah tes kemampuan materi matematika dasar yang berbentuk pilihan ganda. Tes pada penelitian ini dibagi menjadi dua yaitu pretest dan posttest. Soal yang diberikan pada pretest sama dengan posttest sebanyak 10 soal.

Data yang diperoleh adalah data kemampuan matematika dasar yaitu data pretest dan posttest yang berbentuk data nominal. Terlebih dahulu dilakukan uji normalitas dengan menggunakan uji Lilliefors. Dengan menggunakan taraf signifikansi 5\%, didapatkan hasil uji normalitas seperti pada Tabel 1.

Tabel 1. Rangkuman Uji Normalitas Data

\begin{tabular}{lcccc}
\hline $\begin{array}{l}\text { Kemampuan } \\
\text { Matematika } \\
\text { Dasar }\end{array}$ & $\mathrm{L}_{\text {hitung }}$ & $\mathrm{L}_{\text {tabel }}$ & $\begin{array}{c}\text { Keptusan } \\
\text { Uji }\end{array}$ & $\begin{array}{c}\text { Data } \\
\text { Berdistribusi }\end{array}$ \\
\hline Pretest & 0,2259 & 0,1419 & $\begin{array}{c}\mathrm{H}_{0} \\
\text { ditolak }\end{array}$ & $\begin{array}{c}\text { Tidak } \\
\text { Normal }\end{array}$ \\
\hline Posttest & 0,2337 & 0,1419 & $\begin{array}{c}\mathrm{H}_{0} \\
\text { ditolak }\end{array}$ & $\begin{array}{c}\text { Tidak } \\
\text { Normal }\end{array}$ \\
\hline
\end{tabular}

Dari Tabel 1 didapatkan hasil bahwa data kemampuan matematika dasar pada pretest dan postest tidak berdistribusi normal. Oleh karena itu, data pretest dan postest selanjutnya dianalisis dengan menggunakan uji Wilcoxon. Dilakukan uji Wilcoxon karena kedua data pretest dan postest tidak berdistribusi normal setelah dilakukan uji normalitas.

\section{HASIL DAN PEMBAHASAN}

Data yang yang terkumpul adalah data kemampuan matematika dasar pada pretest dan postest. Karena data tidak berdistribusi normal, maka dilanjutkan dengan analisis menggunakan uji Wilcoxon. Peneliti menggunakan uji Wilcoxon dengan software SPSS 20. Deskripsi tentang nilai pretest dan postest dengan uji wilcoxon dapat dilihat pada Tabel 2.

Tabel 2. Deskripsi Pretest dan Posttest

\begin{tabular}{llccc}
\hline & N & $\begin{array}{c}\text { Mean } \\
\text { Rank }\end{array}$ & $\begin{array}{c}\text { Sum of } \\
\text { Ranks }\end{array}$ \\
\hline & $\begin{array}{l}\text { Negative } \\
\text { Ranks }\end{array}$ & $3^{\mathrm{a}}$ & 15,33 & 46,00 \\
Post Test - & Positive & $33^{\mathrm{b}}$ & 18,79 & 620,00 \\
Pre Test & Ranks & $3^{\mathrm{c}}$ & & \\
& Ties & 39 & & \\
& Total & 39 & \\
\hline
\end{tabular}
a. Post Test $<$ Pre Test
b. Post Test $>$ Pre Test
c. Post Test $=$ Pre Test 
Dari Tabel 2 didapatkan hasil sebagai berikut.

1. Negative Ranks atau selisih (negatif) antara tes kemampuan matematika dasar untuk pretest dan posttest adalah 3. Nilai 3 menunjukkan ada sebanyak 3 nilai siswa yang mengalami penurunan (pengurangan) dari nilai pretest ke nilai posttest. Mean Rank atau rata-rata penurunan nilai tersebut adalah 15,33, sedangkan jumlah rangking negatif atau Sum of Ranks sebesar 46.

2. Positive Ranks atau selisih (positif) antara tes kemampuan matematika dasar untuk pretest dan posttest adalah
33. Disini terdapat 33 data positif yang artinya 33 siswa mengalami peningkatan kemampuan matematika dasar dari nilai pretest ke nilai posttest. Mean Rank atau rata-rata peningkatan nilai tersebut adalah 18,79, sedangkan jumlah rangking positif atau Sum of Ranks sebesar 620.

3. Ties adalah kesamaan nilai pretest dan posttest. Ties pada data ini ada 3 nilai siswa yang sama antara nilai pretest dan posttest.

Sedangkah uji hipotesis dengan menggunakan uji Wilcoxon dapat dilihat pada Tabel 3.

Tabel 3. Rangkuman Uji Wilcoxon

\begin{tabular}{lr}
\hline & Post Test - Pre Test \\
\hline$Z$ & $-4,545^{\mathrm{b}}$ \\
Asymp. Sig. (2-tailed) &, 000 \\
\hline
\end{tabular}

a. Wilcoxon Signed Ranks Test

b. Based on negative ranks.

Berdasarkan output yang dapat dilihat pada Tabel 3 bahwa diketahui Asymp Sig (2-tailed) bernilai 0,000. Karena nilai $0,000<0,05$ maka dapat diartikan bahwa ada perbedaan antara tes kemampuan matematika dasar mahasiswa untuk nilai pretest dan posttest. Berdasarkan rata-rata nilai pretest dan posttest didapatkan bahwa rata-rata posttest lebih baik daripada pretest. Penelitian ini sejalan dengan penelitian yang dilakukan Kristanti (2017) yang mengemukakan bahwa melalui metode ekspositori dapat meningkatkan penguasaan siswa dalam materi sifat-sifat bangun ruang. Selain itu, Suniti (2015) juga mengemukakan bahwa pembelajaran ekspositori memiliki dampak positif dalam meningkatkan prestasi belajar siswa pada materi pemfaktoran bentuk aljabar.

\section{SIMPULAN}

Berdasarkan hasil analisis data dan pembahasan didapatkan ada perbedaan antara tes kemampuan matematika dasar untuk pretest dan posttest, sehingga dapat disimpulkan bahwa ada pengaruh penggunaan metode ekspositori pada pembelajaran mata kuliah Matematika Dasar Prodi Manajemen Pendidikan Islam terhadap hasil belajar matematika dasar mahasiswa.

Metode ekspositori yang digunakan dalam proses pembelajaran dapat meningkatkan hasil belajar mahasiswa pada mata kuliah Matematika Dasar. Oleh karena itu, metode ekspositori dapat dijadikan salah satu alternatif dalam melaksanakan proses pembelajaran pada mahasiswa Prodi Manajemen Pendidikan Islam yang kebanyakan lulusan dari SMK atau SMA jurusan Sosial. Selain itu, perlu diadakan pengembangan penerapan metode ekspositori agar dapat lebih optimal dalam meningkatkan hasil belajar mahasiswa. 


\section{DAFTAR RUJUKAN}

Ardhiansyah, N. (2017). "Upaya Meningkatkan Hasil Belajar Matematika Siswa Melalui Penerapan Metode Ekspositori di Kelas VII SMP Negeri 10 Kota Bengkulu". Thesis. Universitas Bengkulu

Hudoyo, H. (1998). Metode Mengajar Matematika. Jakarta: Depdikbud

Kristanti, S. (2017). "Meningkatkan Hasil Belajar Matematika Melaluli Model Pembelajaran Ekspositori Materi Sifat-sifat Bangun Ruang Siswa Kelas V/A SD Negeri 20
Sabang”, Jurnal Ekonomi, Pendidikan dan Sains, I(1), 37-46.

Sanjaya, W. (2006). Strategi Pembelajaran. Jakarta: Kencana.

Suniti, N.M. (2015). "Model Ekspositori Dapat Meningkatkan Prestasi Belajar Matematika dalam Kompetensi Dasar Memfaktorkan Bentuk Aljabar", Jurnal Santiaji Pendidikan, 5(2), 97-102.

Suyitno, A. (2004). Dasar-dasar dan Proses Pembelajaran Matematika 1. Semarang: Unnes 
56 JURNAL PENDIDIKAN EDUTAMA, Vol 5, No 1, Januari 2018 